\title{
The Evolution Of Casualty Evacuation In The 20th Century (Part 4) - An International Perspective
}

\author{
MCM Bricknell
}

\begin{abstract}
This is the fourth in a series of papers that review the evolution of the military casualty evacuation during the 20th Century. The previous three papers have looked at the British Army system. This paper looks at the organisation of army medical services from the United States, Israel, Russia and Croatia and compares these with the British Army system reported in the previous papers. All national army medical services have evolved organisations to reduce the time lag between injury and surgery for their wounded. The paper will show that there are some fundamental differences in the organisation of medical units to achieve this aim. Helicopters are almost universally used for the evacuation of seriously ill casualties when this is practicable.
\end{abstract}

\section{Introduction}

This is the fourth in a series of papers that review the evolution of the military casualty evacuation during the 20th Century. The previous three papers have looked at the British Army system. This paper will consider some reports of field military medical services from other countries. The US Army will be considered in the most detail because there are some fundamental differences in philosophy between their system and that of the British Army in spite of being close military allies. Reports from recent wars involving Israel, Russia and Croatia will also be considered as the medical systems that evolved to support specific types of military operations undertaken by these countries may have some implications for the future.

\section{WORLD WAR 1 1917-1918 US Army}

Lt Col MCM Bricknell DM MMedSci MRCGP MFOM MFPHM DMCC DRCOG RAMC Chief Instructor Defence Medical Services Training Centre, Keogh Barracks, AshVale, Aldershot, Hants, GU12 5RQ. Email:

mcm.bricknell@btopenworld.com
The US Army official history of World War 1 (1) provides much of the information for this section. First aid and splints were applied in the front line trenches where the man fell. The casualty was then carried by regimental medical personnel, or by men from combatant troops detailed for that purpose, to the battalion aid post. At the battalion aid post first aid, splints, and control of haemorrhage was refined. The diagnosis tag was completed and antitetanus serum was administered.
The casualty was then carried by litter bearers detailed from the ambulance section of the sanitary train (the divisional medical unit), to the ambulance dressing station. This was established at the farthest point forward that ambulances could reach with reasonable safety. The main task of the dressing station was the sorting (triage) of the sick and wounded according to the nature of their disability and its degree. The first classification separated the trauma casualties from those with injuries caused by gas, miscellaneous sickness, psychiatric disorders, venereal diseases, skin diseases, and convalescents. The second classification, pertaining to the degree of disability, ranged from malingerers to fatal wounds or illness. Patients in the first class were returned to duty; those in the second class were sent to hospital, walking or sitting; those in the third class were sent recumbent to hospital; while patients in the fourth class were held until they rallied and then were evacuated with exceptional care. The motor ambulances of the company operating the dressing station undertook evacuation of patients from the dressing station to the field hospital.

TRIAGE: by disposal: return to duty, walking or sitting wounded, lying wounded, unfit to move.

The sanitary train of a division was composed of four motor ambulance companies (three light and one heavy), four motorized field hospitals, one litter bearer battalion, one medical supply unit, and one laboratory unit. The field hospitals were more aligned to the role of the Main Dressing Station than the Casualty Clearing Stations of the British Army. The function of the field hospital was to provide food and temporary shelter, medical, and surgical care for the sick or injured divisional troops in combat or on the march. A field hospital was a standard unit, designed with a view to mobility. Every effort was made to maintain one hospital in reserve for use in an advance or retreat, and a hospital once established would not be closed except by order of the director of medical services.

If the terrain permitted, the four field hospitals of a division were placed together. They were plainly marked by the Red Cross emblem in order to protect them from 
enemy fire. Placing the field hospitals together was found to have certain definite advantages: ambulance drivers located them without difficulty, they were more easily administered and assistance from the field hospital in reserve was immediately available. Field hospitals were designated as follows: gas hospital, hospital for nontransportable wounded, hospital for minor sick (including skin and venereal diseases) and one hospital in reserve (2). These were to be grouped in one place approximately 10-12 kilometres from the front so as to be out of range of enemy artillery fire. The hospital for non-transportable wounded mirrored the French arrangement in the provision of mobile field surgical ambulances placed forward within the divisional area, near to the division triage unit (3). These had two surgical teams and 50 beds supported by female nurses.

\section{FIELD HOSPITALS: role specialisation with triage forward of the hospital units.}

The US medical service copied the format of 2 French medical units, the mobile hospital (auto chir) and the mobile surgical unit (groupe complemataire). The former consisted of an operating room truck, with operating tables and other equipment, an X-ray truck, a sterilising truck, a kitchen truck and a truck for tentage and bedding. It had the following departments: (1) Receiving, triage or sorting; (2) shock ward; (3) X-ray department; (4) operating room; (5) pharmacy, laboratory, dental; (6) mess (patients, officers, nurses, enlisted personnel); (7) evacuating; (8) office (commanding officer, adjutant, quartermaster); (9) morgue. It occupied 22 tents and had a capacity of 250 patients. The ground plan of a mobile hospital is shown at Figure 1.

These mobile hospitals were sent to the army area to be under the control of corps surgeons, very similar to the light section of a British Casualty Clearing Station. They were provided in the proportion of one to every combat division in the corps. These hospitals were placed in the corps or division area according to the orders of the corps sanitary train commander to the director of corps field hospitals. The mobile surgical unit consisted of a portable sterilising unit, X-ray, electric lighting plant, a light frame operating room and surgical materiel mounted on 2 trucks. It could not function independently but was designed to supplement the advanced field hospital of a division. Thus there were two options for the provision of immediate surgical aid to the nontransportable wounded. They were placed as close to the division triage as possible but care was taken to ensure that they would not be placed too far forward in case of a sudden retreat or in direct range of enemy artillery.

\section{MOBILITY: mobile surgical \\ hospitals and mobile surgical teams allowing grouping of surgical capability}

The wounded were transported to evacuation hospitals from the mobile surgical hospital (corps) or from the various field hospitals by ambulance companies under orders of the corps surgeon, assisted by the

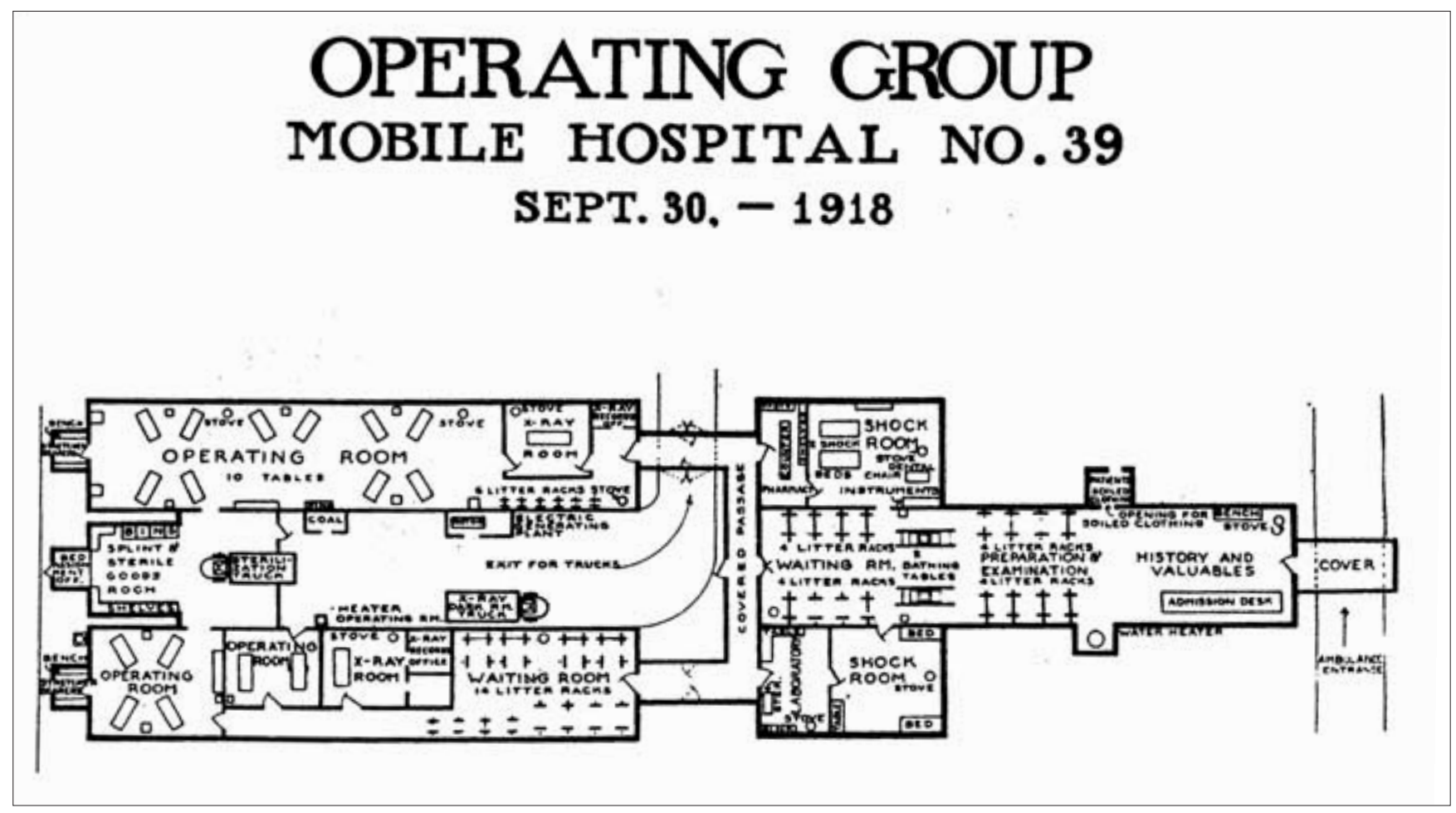


army ambulance service assigned to evacuation duty when requested. Patients were then moved to base hospitals and then to hospital ships back to the USA.

\section{World War II 1942-1945}

Mediterranean And Europe 1943-1945

The US invasion force for Tunisia was the first independent Army deployed to create a Theatre of Operations. The only hospital designed for forward surgery was 48th Surgical Hospital. This was a mobile hospital with 3 functional units, an operating unit and two holding units with cots. In the advance, the operating unit functioned in conjunction with one holding unit. When needed forward, the operating unit was designed to move forward with the second holding unit, leaving the first to care for its nontransportable wounded until they were ready to be evacuated (4). In reality this hospital was not only too heavy for mobility but also poorly equipped. An initial method to provide forward surgery was achieved

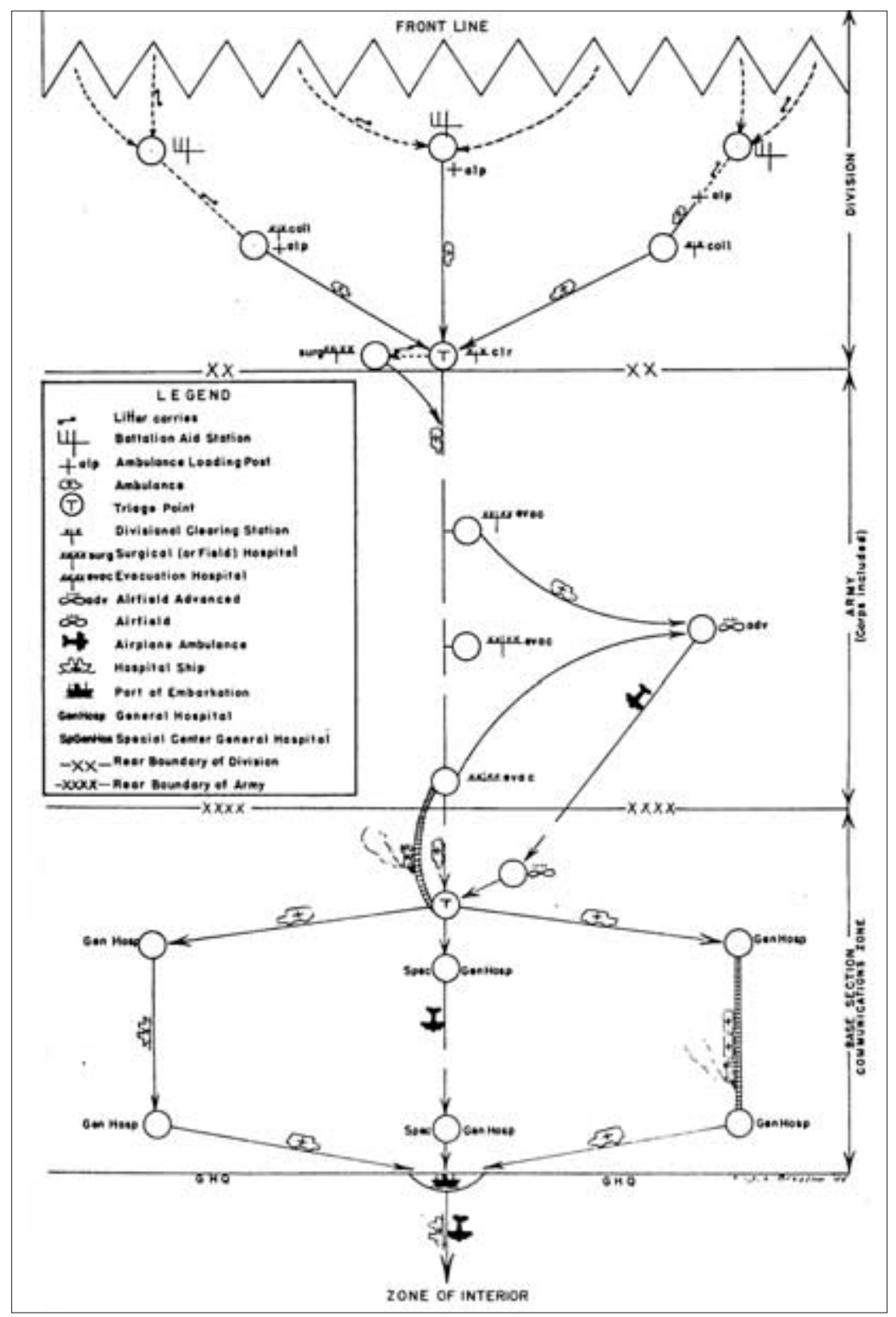

Fig 2. The US Army Organisation of Evacuation in a Theatre of Operations. through the attachment of surgical teams and shock teams from 2nd Auxillary Surgical Group and field hospitals to Clearing Platoons of divisional medical battalions. This system was not supported by an efficient triage system so that these composite units functioned as miniature evacuation hospitals performing initial surgery on as many casualties as they could.

The US Army in the Mediterranean Theatre, and later the Northern European Theatre, adopted the 'three-point forward system' described by Jolly (5) after the Spanish civil war. Each battalion had a medical officer and a number of medical corps assistants. Each division had a medical battalion organised into 3 collecting companies (consisting of stretcher bearers and ambulances) and a clearing company (equivalent to a British Dressing Station) (6). The medical staff in North Africa organised forward first-priority surgery with a wellequipped field hospital platoon staffed by surgical teams from a field hospital reorganised and equipped for this specific mission. This unit was located in physical conjunction with the clearing station triage point in the divisional area. Thus the severely wounded could be immediately transferred from the clearing station to the hospital platoon by hand litter thus removing any delay resulting from resuscitation or interference with splinting or dressings outside the surgical unit. Expert surgical treatment embracing resuscitation, operation and prolonged post-operative care was immediately available (7). Field hospitals were divided into a headquarters and three hospitalisation units. The surgical teams were provided with two $2 \frac{1}{2}$-ton trucks with sufficient tentage, instruments and supplies. The hospital platoon held and cared for the wounded after operation. This platoon consisted of 6 officers, 5 nurses and 32 other ranks and could hold 134 patients on wooden cot beds (8). Some wondered whether a new unit might perform this better than an improvisation using portions of 3 units, a complete mobile surgical hospital (9).

Field Hospitals could be reinforced by mobile surgical teams. These were provided with a general surgeon, an assistant as an orthopaedic surgeon, an anaesthetist, 3 operating room technicians and a shock team of 1 officer (preferably a physician) and 2 technicians. These independent mobile surgical units were part of 2nd Auxiliary Surgical Group in the Mediterranean Theatre and 3rd Auxiliary Surgical Group in Northern Europe. These could be used separately from hospital platoons, for example in the plan for the invasion of Italy, nine teams of the 2nd Auxiliary Surgical Group were to be in the assault wave, attached to the divisional clearing platoons and to the beach battalion. 


MOBILITY:
separating surgical capability from
holding capability to allow
regrouping of surgical assets while
holding facilities clear casualties

As soon as a patient needing further care could be safely moved, he was sent back to the nearest 400-bed evacuation hospital within easy ambulance haul. These Evacuation hospitals handled the transportable severely wound, the patients with minor injuries and most of the sick. They were organized and their tents laid out with the efficiency of the surgical service as the main consideration. In periods of heavy combat, evacuation hospital surgeons worked as teams in 12- and sometimes 16hour shifts, with operating rooms continuously in use. The maximum holding period was seven days. Whenever possible, the severely wounded were then evacuated by air from forward airfields (10).

Although the US Army started in Italy with one evacuation hospital per division, additional hospitals were created in the army area and two evacuation hospitals were assigned to receive casualties from each division. One hospital took all admissions for twenty-four hours; then closed to catch up and rest its personnel while the other took over for a similar period. This system, proved only partially successful, since the casualty load varied markedly from day to day with the progress of the fighting. The next plan provided for the Army Evacuation Officer notifying Corps Evacuation Officers how many surgical and how many medical cases they might send in the course of the day to each hospital in stated sequence. Under this system, no hospital would be overburdened unless the aggregate casualties for the day exceeded the combined quotas of all the hospitals in the area (11).

CASUALTY REGULATION:
forward planning of the allocation of
clinical workload to evacuation
hospitals

Pacific Front 1942-1945

After the fall of the Philippines, the Allied campaign in the Pacific was characterised by a series of amphibious invasions with the aim of capturing islands progressively closer to the Japanese mainland. Each was a nest of Japanese strongholds hidden in bunkers and thick jungle. The scheme of evacuation from the front line started with initial treatment by a medical aidman followed by a stretcher carry to the battalion aid station located as close to the scene of action as possible. This distance varied from 200 to 1000 yards, usually about 300 yards. The aid station was sited in close proximity to the front line, in order to shorten the time taken to provide advanced first aid to battle casualties, and to reduce the difficulty in evacuation due to the shortage of litter bearers and the type of terrain in which they worked.

The difficulties of vehicle transport so close to the front-line led to the creation of 25-bed Portable Surgical Hospitals consisting of four medical officers and thirty-three enlisted men (12). These were designed to accompany invasion forces, to work on the beaches and move forward inland with the troops to provide lifesaving treatment and stabilisation prior to evacuation to the rear (13). Each hospital could be used whenever needed - as a surgical hospital, a treatment hospital or an evacuation hospital along the route of evacuation. Where possible, and the terrain permitting, the collecting platoon and the portable hospital functioned in close proximity to each other behind the battalion aid station. The distance between the battalion aid station and the portable hospital was usually twenty to thirty minutes litter carrying time. This distance was approximately from 800 yards to 1200 yards to the rear of battalion aid stations, out of range of small arms fire. The choice of a site for a portable hospital was limited. It had to be near a trail to the front line, and, in almost every situation there was only one trail. This made for faster receipt of patients from the front and enabled the personnel to perform their life saving surgery in comparative safety. The collecting platoon operated an aid station in the vicinity of the portable hospital. All sick and wounded coming down the trail came through the collecting platoon and were separated. Those needing immediate surgery were taken to the portable hospital and those not so seriously wounded and those too ill to remain in the area were sent down to the clearing station. The patients who might be returned to duty within two or three days remained at the collecting platoon for treatment until returned to duty.

\section{FORWARD SURGERY: creation of Portable Surgical Hospital to provide live-saving surgery forward.}

The clearing station was usually located some two miles to the rear and all cases to be evacuated came through there. Surgery could also be performed at the clearing station. Medical cases that might be returned to duty remained there for treatment. Further evacuation was to Evacuation hospitals on land or to hospital transport ships in the amphibious shipping group.

\section{Korea}

After World War II the medical planners in the US Army designed a medical unit that combined the function of a clearing station (from the Divisional medical battalion), hospital platoon (from a field hospital) and 
mobile surgical unit (from the Auxiliary Surgical Unit). The Mobile Army Surgical Hospital, a sixty bedded unit equipped for surgery with its own vehicles and infrastructure, was established in 1948 (14). It had 14 doctors (3 surgeons, 2 anaesthetists, one radiologist, 3 assistant surgeons, 2 physicians and 3 general duties medical officers), 12 nurses, 2 medical service corps officers, one warrant officer and 93 other ranks (15).

Although the US Army had 5 MASHs on paper, none were available in the Far East at the start of the Korean War. During the initial stages of the campaign, hospital support was critically short. Three MASHs were started from scratch, 8055, 8063 and 8076. In the first 6 months of the War, nearly all the United Nations casualties requiring immediate surgical treatment received it from a MASH (one further MASH, 1st MASH, deployed for the invasion at Inchon) whose bed capacities were increased from 60 to 150 by November 1950 . After surgery and stabilisation the wounded soldier was evacuated to one of three 400-bed semimobile evacuation hospitals. From there the evacuation chain led back to Japan and then the United States (16).

After the battlefront had stabilised in 1951, the situation existing during the Korean conflict was almost ideal for casualty care. The battle line was stable; control of the air was in friendly hands enabling widespread use of helicopter evacuation; and the forward hospitals were situated close to the battlefront. The MASH became a more stable unit and tents were gradually replaced by prefabricated huts.

\section{Vietnam}

Vietnam was a jungle conflict fought as a counter-insurgency campaign against the Viet Cong and a more conventional fight against the North Vietnamese Army. Surface evacuation of the wounded was almost impossible as there was no secure road network in the combat area of Vietnam. Early in the war, it was found that relatively small numbers of helicopters with an exclusive medical mission could evacuate large numbers of patients to centrally located medical facilities. Helicopter evacuation under the control of the medical services, in addition to moving casualties swiftly and comfortably from the battlefield to supporting hospitals, proved to be an important tool of modern military medical management permitting more efficient and more economical use of medical resources. Hospitals moved infrequently, with little expensive "downtime" and loss of continuous support. Surgical lags were reduced. It was no longer necessary to staff every hospital with every specialty, because the casualty was directed to that hospital best suited for the special attention he needed (17).

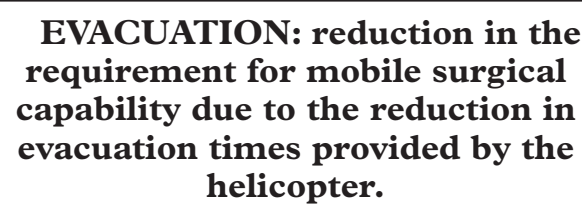

EVACUATION: reduction in the requirement for mobile surgical capability due to the reduction in evacuation times provided by the helicopter.

Semi-permanent hospitals, located in base areas, with sophisticated equipment, with airconditioned surgical and recovery suites and intensive care wards, permitted the application of the latest techniques of modern medicine in the forward battle area. All Army hospitals in Vietnam, including the MUST (Medical Unit, Self-contained, Transportable) units, were fixed installations with area support missions. MUST-equipped surgical hospitals were operated for several years, in Vietnam with mixed success. These units consisted of three basic elements, each of which could be airlifted and dispatched by truck or helicopter. The expandable surgical element was a self-contained, rigid-panel shelter with accordion sides. The airinflatable ward element was a double-walled fabric shelter providing a free-space area for ward facilities. The utility element or power package contained a multi-fuel gas turbine engine which supplied electric power for airconditioning, refrigeration, air heating and circulation, water heating and pumping, air pressure for the inflatable elements, and compressed air or suction. In addition, other expandable shelters were used for central materiel supply, laboratory, X-ray, pharmacy, dental, and kitchen facilities. Revetments were raised around all inflatable MUST components to make them less vulnerable during attacks.

\section{HOSPITAL CAPABILITY: increasing hospital capability increases hospital infrastructure and logistic footprint.}

Because hospitals supported operations from fixed locations, emphasis was placed on the selection of a hospital site in a reasonably secure area. Proximity to tactical operations was a consideration only in the sense that the hospital had to be within reasonable airevacuation time and distance. Hospitals had to be moved only when major tactical forces shifted to open new areas of operations. MUST equipment was a link in such hospital relocations. Pending the construction of fixed facilities in new areas MUST hospitals provided the controlled environment and the other resources needed for high-quality patient care. As air-conditioned fixed hospitals were completed, the need for MUST equipment diminished.

Longer term care for patients suffering from malaria and hepatitis, or recuperating from surgery was also provided in the region. The convalescent centre at Cam Ranh Bay 
and the medical facilities in Japan enabled many soldiers to be returned to Vietnam rather than evacuated back to the USA.

CLINICAL CAPABILITY: military medical systems require capability and capacity for medical cases in additional to surgical cases

\section{UP TO THE GULF WAR AND BEYOND}

Although a network of semi-permanent hospitals supported operations in Vietnam, the basic evacuation chain for mobile military operations remained the same as for the Korean War. The patient evacuation flow shown in the manual for medical support in a theatre of operations is reproduced at Figure 2 (18). The MASH continued to provide resuscitative surgery and medical treatment necessary to prepare critically injured or ill patients for further evacuation.

The concept of the Airland Battle, developed in the early 1980s, transformed US military thinking. The US Army Medical Department revised its concepts for health service support in response to this change (19). There were to be three hospitals: the Combat Support Hospital (CSH) for the treatment of patients who would return to duty, the Evacuation Hospital to stabilise those patients who need to be evacuated out of the Theatre and the General Hospital for the continued treatment for stabilisation of those patients evacuated from the combat zone.

The MASHs were to be phased out and replaced by the Forward Surgical Team (FST), initially called a Mobile Surgical Platoon from the CSH. This unit was designed to provide a rapidly deployable immediate surgery capability for otherwise non-transportable patients. It is a 20 person unit organised into four functional areas: triage/trauma management, surgery, recovery and administration/operations. It is able to receive and manage approximately 10 patients per day (20).

\section{MOBILITY: the MASH increased in size during the Vietnam War and thus a new unit, the FST, was function of the MASH}

\section{Gulf War}

The Gulf War occurred whilst the US Army Medical Department was undergoing this reorganisation. Three types of hospital were deployed, MASHs, CSH and Evacuation Hospitals totalling some 44 hospitals and 13,000 beds (21). It was decided to organise these as groups by type rather than in a linear system so that evacuation was controlled by movement between groups of hospitals rather than along a proscribed line from division to $\mathrm{MASH}, \mathrm{CSH}$ then evacuation hospital. The deployment called for a variety of innovations, for example 5th MASH was tasked to develop a mobile, surgically intensive unit. It was found that the FST of 2 operating tables and 22 persons was likely to become quickly exhausted. Therefore, a composite unit was formed from elements of 702nd Clearing Company, FST and MASH. This organisation was called the Forward Surgical Element and used conventional medium and large canvas tents. It was highly mobile and took only 2 hours to set a 4 table operating theatre supported by 60 beds (including $12 \mathrm{ICU}$ ). The MASH itself was lightened to 36 ICU beds and used Deployable Medical Systems (DEPMEDS) ISO shelters and the heavier Tent, Expandable Modular Personnel (TEMPER) tents. The complete MASH took 2 days to set up to produce 60 ICU beds and 4 operating tables and was not $100 \%$ mobile (22).

The US Army continues to shift from a forward deployed (ie. based around the world) to a continental US-based Force Projection Army. The medical services emphasise far forward medical treatment, including advanced trauma management and far forward surgery. Standardized medical units using a modular-designed medical support system including flexible, responsive, and deployable hospitals are being designed and structured to support this task. Casualties whose wounds or injuries will not allow for immediate evacuation out of the division will receive immediate surgical care in order to stabilize them for evacuation. The requirement to project resuscitative surgery far forward will increase as a function of the extended battlefield. Forward Surgical Teams (FST) will meet this need in support of brigadesized units. Surgical stabilization of otherwise non- transportable casualties is the focus of these forward surgical teams. The FSTs will have the capability to select (triage) surgical candidates, provide pre-operative treatment, surgical stabilization, and postoperative recovery. Generally, FSTs will be corps assets, and employed with, or attached to, a brigade or divisional medical unit in support of combat operations. The FSTs will be attached to corps hospitals when not employed in the division. Theatre hospitals will provide definitive care to all patients who will either be returned to duty or stabilized for evacuation out of the corps or back to the US (23). This is summarised in Figure 3.

\section{OTHER NATIONS}

This section describes a series of vignettes from reports of the medical support to the Israeli, Russian and Croatian armies. This provides a flavour of developments in military medical support as a result of the experience of differing types of military operations. 


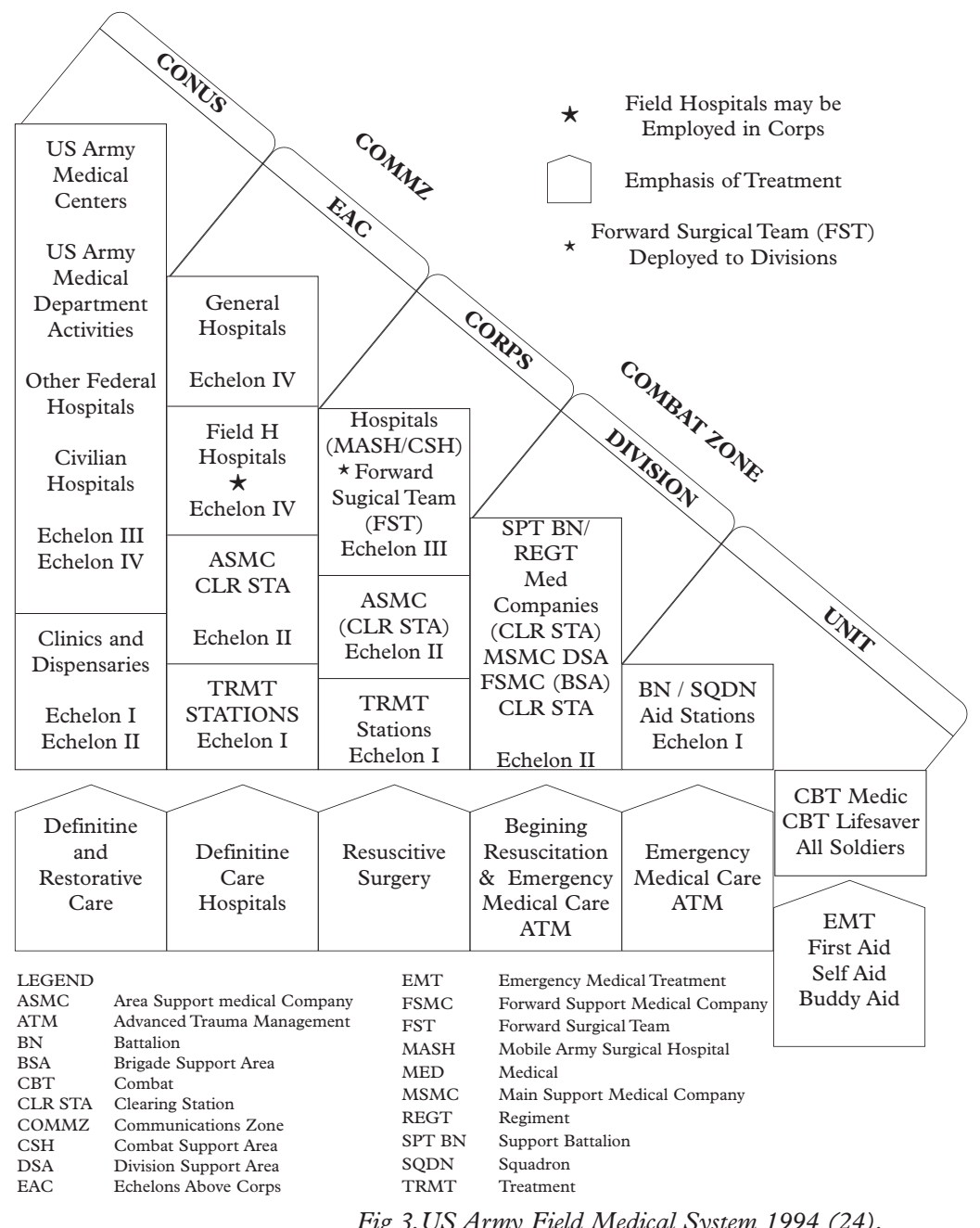

Fig 3.US Army Field Medical System 1994 (24).

\section{Israeli Experience}

The challenge facing the field medical services of the Israeli Army is different to that of the British and United States Armies. The threat to Israel is from its neighbours so the Israeli Defence Force (IDF) conducts operations very close to national civilian hospitals and, therefore, there is no requirement for a long casualty evacuation chain (25). The IDF concentrates most of its resources in forward areas of the battlefield. Helicopters are used extensively for casualty evacuation. Hospitalisation of wounded is controlled at a national level and involves the regulation of military casualties to the most appropriate facility utilising all hospital beds within the country. The same proximity of civilian hospitals to the front line might also put these facilities at risk and so the IDF has mobile surgical units and field hospitals to provide a reserve capability, should the civilian hospitals be damaged or overwhelmed by large numbers of civilian casualties (26).

\section{CASUALTY REGULATION: national control of hospital capacity to support military operations}

The basic organisation of the field medical services is similar to the US Army system with a medical aid station supporting the forward battalions and a medical battalion (composed of medical companies and platoons) supporting combat divisions. In the 'Yom Kippur War' of October 1973 the medical battalion also contained a surgical company comprising a surgical team, a triage facility and a holding platoon. This company was designed to provide sophisticated resuscitation and, in extreme cases, surgery for casualties who would not survive further evacuation without intervention. In the Northern front casualties were then evacuated to civilian hospitals, whereas in the Sinai (Southern front) a field hospital was established as an intermediate node because of the extended distances for evacuation (27).

The Lebanon War of 1982 provided a further test of the IDF medical systems. The majority of casualties were evacuated by helicopter from the company of a medical battalion directly to a rear hospital (26). Surgical companies of divisional medical battalions were available to provide forward surgery as in 1973. The IDF evaluated a combined surgical and intensive care unit based on US designed expandable ISO containers in July 1982. This unit was considered to be a breakthrough in providing an 'adequate' environment for performing lifesaving surgical and other resuscitative procedures. It was recommended that this unit should be allocated to units or regional areas rather than considered as an organic part of a divisional medical battalion (28).

The IDF retains these capabilities and has also developed a complete air-transportable field hospital. This unit has seen extensive service in support of humanitarian operations during the 1990s including Armenia, Rwanda (29) and Kosovo (30). The advantage of a military medical unit is that it is self-contained for vehicles, generators, forklift and a small tractor/digger. This includes all the general equipment needed such as tents, kitchen and accessories, water heating, laundry, lighting and communication systems, and equipment for electrical and mechanical maintenance.

\section{Russian}

Soviet field medical support is based on multistage evacuation with minimal treatment at each stage (31). The basic scheme follows the conventional aid station at battalion level, dressing station at brigade level and a divisional clearing station. Casualties are sorted into chemically contaminated cases, infectious cases, walking wounded, transportable lying cases and shocked cases. There is an operating theatre and a holding capacity for 60 patients to provide life and limb saving surgical care for 
the most seriously injured. The sorting physician in the divisional medical point directs the casualty to one of several specialised surgical field hospitals according to the type of injury.

Grau and Jorgensen reviewed the Russian military medical experience in Afghanistan and Chechnya (32). These were not conventional wars between government armies, rather counter-guerrilla campaigns. Soviet medical evacuation procedures changed to meet the demands of the environment. Helicopter evacuation was the primary means of evacuation once out of the direct fire battle. The regimental medical post (dressing station) was frequently bypassed as wounded were evacuated directly from the battalion aid station to the division field hospital or one of the army hospitals. The regimental medical post still handled the sick, who were a major problem in the Russian Army.

The division's medical battalion ran a field hospital which could handle up to 400 patients every 24 hours, conduct surgery and run a 60 bed recovery facility. The Soviets formed special surgical teams that were integrated as reinforcements into medical battalions to support projected military operations. The senior medical officer formed the reinforced medical battalion into a triage group and a specialty surgery group that performed thoracic, abdominal, neurosurgical, trauma, vascular and also general surgery.

\section{Croatian}

During the 1991/1995 civil war Serbian paramilitary forces occupied a significant proportion of the territory of Croatia. The Croatian Armed (CA) forces (Police and Army) resisted this invasion. The CA medical corps was formed from the civilian ambulance service and used civilian hospitals for definitive care of casualties (33). The absence of helicopters and the terrain (many battles were fought in woods) reduced the possibilities for quick transportation of the wounded and so the only way to shorten the time from injury to treatment was to bring surgery to the front lines. Mobile Surgical Hospitals (MSH) were organised to meet this task (34). For example, in Rama in 1992, a mobile surgical hospital was set up within 1 - $5 \mathrm{~km}$ from the front line. This unit was organised into 4 sections, an emergency department, a 2 table operating theatre, 4 bed intensive care unit and a 20 bed ward. In addition there was X-ray and laboratory support (35). This evolved into a network of Mobile Surgical Hospitals across the front lines (34).

SURGERY: forward surgical units
required to meet clinical timelines if
casualty evacuation is likely to be
delayed

\section{Summary}

This section has described how the US Army system of medical support in the field has evolved during the 20th Century. This system is different to that of the British Army in that a mobile hospital facility (as a complete unit) has evolved to work alongside the divisional clearing station to provide forward surgical support. This unit evolved from the Mobile Surgical Hospital of the First World War, the Hospital Platoons and Portable Hospitals of the Second World War, the Mobile Army Surgical Hospital of the Korean, Vietnam and Gulf Wars to the Forward Surgical Team of today. The Israeli, Russian and Croatian reports mirror this philosophy. Both the US Army and the Israeli IDF developed containerised medical shelters during the 1980s and this is now mirrored across many other nations (French and Dutch armies to name two). Helicopter evacuation of seriously injured casualties is also widespread, where resources and terrain allow.

This project was supported by a shortterm research fellowship in the history of medicine from the Wellcome Trust.

\section{References}

1. Lynch C, Ford JH, Weed FW. The Medical Department of the United States Army in the World War Volume VIII Field Operations Government Printing Office Washington 1925.

2. Grissinger JW. Medical Field Service in France. Association of Military Suregons. Washington DC. 1928.

3. Fauntleroy AM. Report on the Medico-military aspects of the European War. Department of the Navy. Washington DC. 1915.

4. Churchill ED. Surgeon to Soldiers. Lippincott. Philapdelphia.

5. Jolly DW. Field surgery in total war. Hamish Hamilton. London. 1940.

6. Wiltse. United States Army in World War II. The Technical Services. The Medical Department: Medical Service in the Mediterranean and Minor tehares. Centre for Military History. US Army. Washington DC. 1987.

7. Churchill ED. The surgical management of the wounded in the Mediterranean Theatre at the time of the fall of Rome. Ann Surg 1944;120:268-283.

8. Blackham RJ. The American Army Medical Services in the Field. F R Army Med Corps 1946;86:201-205.

9. Cosmas GA and Cowdrey AE. United States Army in World War II. The Technical Services. The Medical Department: Medical Service in the European Theatre of Operations. Centre for Military History. US Army. Washnigton DC. 1992.

10. Chapter VIII. European Theatre of Operations. Medical Department United States Army In World War Ii Organization And Administration In World War II Ed. Charles M. Wiltse. Office Of The Surgeon General Department Of The Army Washington, DC, 1963.

11. Chapter VII. The Mediterranean Theatre of Operations. Medical Department United States Army In World War II Organization And Administration In World War II Ed. Charles M. Wiltse. Office Of The Surgeon General Department Of The Army Washington, DC, 1963.

12. Table of Organisation and Equipment. No 8-572. Portable Surgical Hospital. War Dept. Washington 14 Dec 1944.

13. Condon-Rall ME, Cowdrey AE. United States Army in World War II. The Technical Services. The 
Medical Deaprtment: Medical Service in the War against Japan. Centre for Military History. US Army. Washington DC. 1998.

14. Table of Organisation and Equipment. No 8-571. Mobile Army Surgical Hospital. Department of the Army. Washington. 28 Oct 1948.

15. Apel OF, Apel P. MASH An Army Surgeon in Korea. University Press of Kentucky. 1998.

16. Cowdrey AE United States Army in the Korean War. The Medics' War. Centre for Military History. United States Army. Washington DC. 1987.

17. Vietnam Studies Medical Support Of The U.S. Army In Vietnam 1965-1970 By Major General Spurgeon Ned Department Of The Army Washington, DC, 1973.

18. FM 8-10 Medical Support. Theatre of Operations. Headquarters Department of the Army. Washington April 1970.

19. US Army Operational Concept for Health Service Support to the Airland Battle. Tradoc PAM 525-50 11 Apr 1986

20. Employment of Forward Surgical Teams. FM 8-1025. HQ Department of Army. 1997.

21. Ledford FF. Medical Support for Operation Desert Storm. The Journal of the US Army Medical Department 1992; Jan/Feb:3-6.

22. Steinweg KK. Mobile Surgical Hospital Design: Lessons from 5th MASH surgical packages for Operations Desert Shield/Storm. Milit Med 1993;158:733-739.

23. Operational Concept For Combat Health Support TRADOC Pamphlet 525-50 1 October 1996.

24. Employment of the Combat Support Hospital. FM 8-10-14. Dec 1994.

25. Israeloff J. Medical Field Service in the US Army Medical Department and the Israeli Defence Forces. Milit Med 1985;150:416-422.
26. Dolev E. Medical services in the Lebanon War, 1982: An Overview. Isr F Med Sci 1984;20:297-299.

27. Alder J. Organisation of the evacuation and management of casualties during the October 1973 War. Paper presented at the 8th International Advanced Course for Young Medical Officers 1977.

28. Gasko OD. Surgery in the field during the Lebanon War, 1982: Doctrine, experience and prospects for future changes. Isr f Med Sci 1984;20:350-54.

29. Heyman SN, Eldad A, Wiener M: Airborne field hospital in disaster area: Lessons from Armenia (1988) and Rwanda (1994). Prehospital and Disaster Medicine 1998;13(1):21-28.

30. Donchin Y: Israeli Field Hospital for Kosovo Refugees in Macedonia. The Internet Journal of Rescue and Disaster Medicine 1999; Vol1N2: http://www.ispub.com/journals/IJRDM/Vol1N2/ref ugee.htm.

31. Medical Support of the Soviet Ground Forces. DDB-1150-18-79. Department of Defense Intelligence. Washington DC. 1978.

32. Grau L, Jorgensen WA. Handling the Wounded in a Counter-Guerrilla War: the Soviet/Russian Experience in Afghanistan and Chechnya. Foreign Military Studies Office, Fort Leavenworth, KS 1998.

33. Butkovic S, Bkic K, Puntaric D, Petrovicki Z. Medical corps support to a Brigade offensive action including river crossing. Milit Med 1995;160:408411.

34. Lovric Z, Mihaljevic J, Martinac M. Mobile surgical teams of Craotian special police forces: analysis of casualties during combat. Milit Med 1997;162:360-362.

35. Radonic V, Aras N, Pavic A. Organisation and functioning of the front line surgical station at Rama in Bosnia and Herzegovina. Milit Med 1993; 158: 763-766. 